\title{
Zosteriform cutaneous squamous cell metastasis from carcinoma cervix - a rare case report
}

\author{
Romita Bachaspatimayum¹, Bishurul Hafi', Pradeepa Duraswamy', Th. Bipin² \\ ${ }^{1}$ Department of Dermatology, Venereology and Leprosy, Regional Institute of Medical Sciences, Imphal, Manipur, India, \\ ${ }^{2}$ Babina Diagnostics, Imphal, Manipur, India
}

Corresponding author: Dr. Romita Bachaspatimayum, E-mail: dr.romita.bachaspatimayum@gmail.com

\begin{abstract}
A 49 year old women presented in out-patient department with itchy, papulo-nodular lesions on the left side of the neck and upper trunk in dermatomal distribution of three months duration. She was earlier diagnosed with squamous cell carcinoma of cervix and was on follow-up for the past one year after completing chemo-radiation. A diagnosis of zosteriform metastasis was made and biopsy was taken from a representative sample which showed moderately differentiated squamous cell carcinoma. Majority of these cases in the past have been misdiagnosed as herpes zoster and were treated with antiviral drugs. Hence metastatic diseases might be considered as the differential diagnosis of zosteriform rash in known cases of squamous cell carcinoma cervix.
\end{abstract}

Key words: Cutaneous metastasis; Zosteriform pattern; Carcinoma cervix

\section{INTRODUCTION}

Carcinoma cervix is the most common gynaecological malignancy which usually metastasise to lungs and liver. Cutaneous metastasis is very rare in carcinoma cervix, ranging from $0.1-4.4 \%$ only [1]. Out of them a very few cases presented in linear or zosteriform fashion. To our best knowledge no cases of zosteriform metastasis from squamous cell carcinoma (SCC) of cervix has been published in English literature yet.

\section{CASE REPORT}

A 49 year old multiparous woman presented with itchy skin lesions over left side of root of neck and upper chest for the past three months (Figs. 1 and 2), which was aggravated on sweating and on exposure to sunlight. It started along the neck and gradually spread to upper chest. One year back she was diagnosed with squamous cell carcinoma of uterine cervix and had undergone chemo-radiation. Cutaneous examination revealed grouped shiny papules, nodules and plaques over left side of neck and upper chest, not crossing the midline in a dermatomal fashion along C4, T1 and T2. Stony hard, matted, mobile, non tender lymph nodes of $3 \mathrm{~cm} \times 2 \mathrm{~cm}$ were present in left upper cervical group. Hard, single, mobile lymph node of $1.5 \mathrm{~cm}$ x $1 \mathrm{~cm}$ was present in left lower cervical group. Left supra clavicular lymph node was also enlarged, two in number, $0.5 \mathrm{~cm} \times 0.5 \mathrm{~cm}$, hard and mobile. Right side of the neck and the trunk were normal. Clinical examination of breasts was normal. Oral cavity was also normal. A provisional diagnosis of zosteriform cutaneous metastasis was made. Chest and ENT consultation was done to rule out other primary sites. Her blood routines and radiological investigations including CT thorax were within normal limits. Skin biopsy of the representative sample taken from the neck lesion showed skin with dermis showing malignant squamous cells arranged in clusters and singles infiltrating the stroma with irregular margins. Overlying epidermis is uninvolved. Features were of metastatic squamous cell carcinoma (Fig. 3). Patient was advised Fine needle aspiration cytology (FNAC) of the enlarged cervical and supraclavicular lymph nodes and was referred to Radiotherapy department of the Institute but was lost to follow-up. Prior to the study,

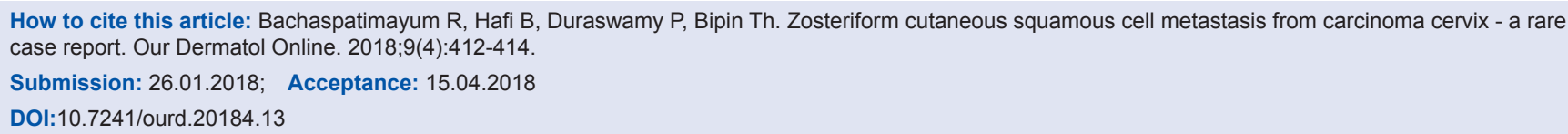




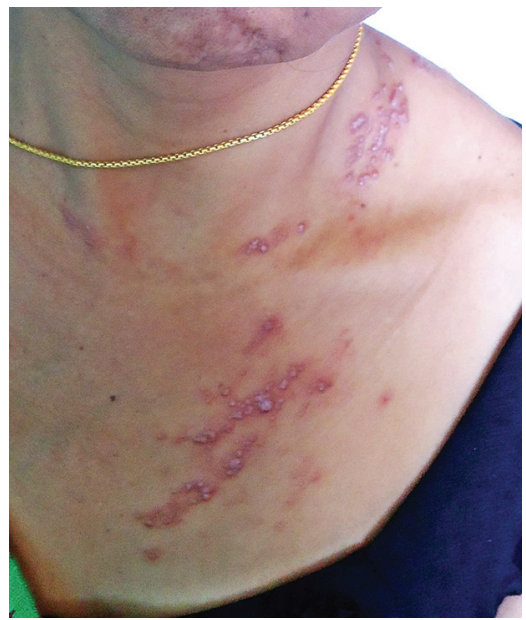

Figure 1: Grouped shiny papules, nodules and plaques over left side of neck and upper chest in a dermatomal fashion.

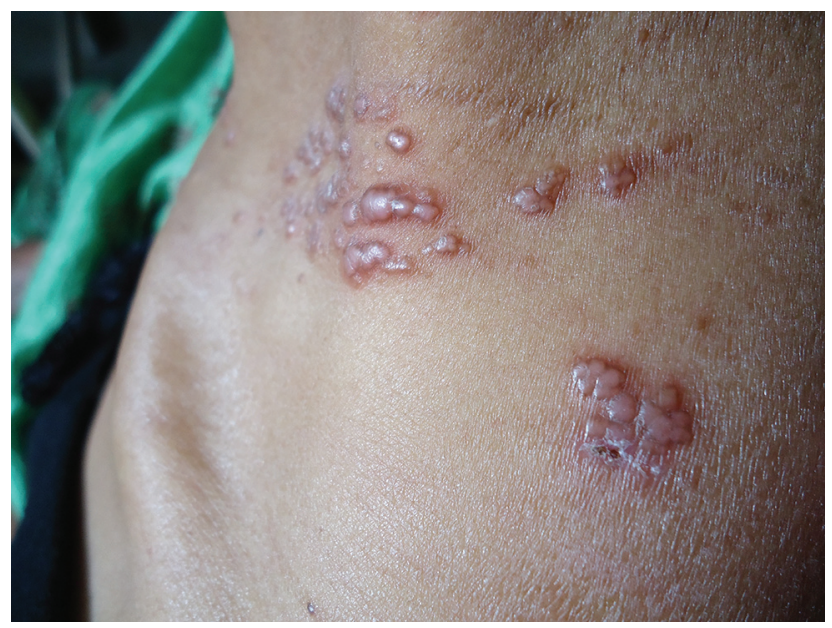

Figure 2: Close-up view of Figure1.

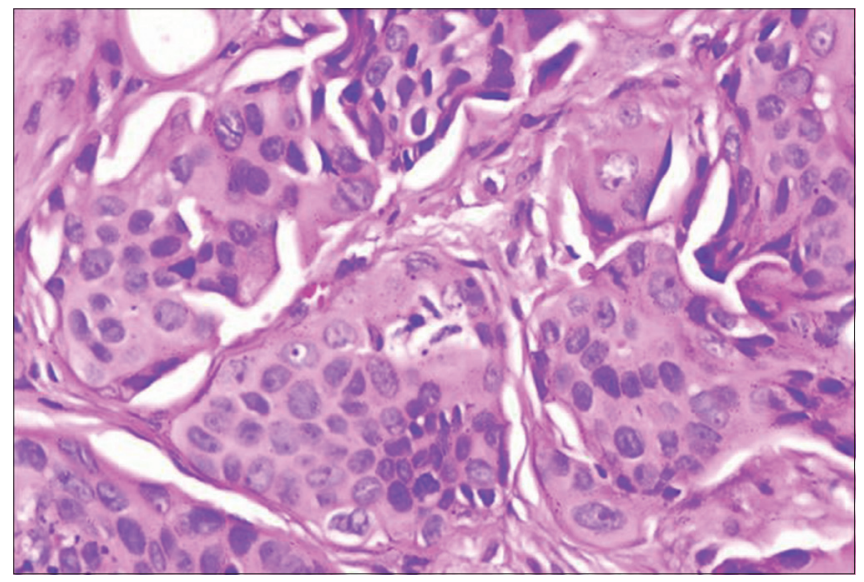

Figure 3: Moderately differentiated squamous cell carcinoma. H.P.E. (H\&E, 10x).

patient gave written consent to the examination and biopsy after having been informed about the procedure.

\section{DISCUSSION}

Cervical cancer is one of the most common malignancy affecting women in India. It frequently metastasizes to lungs, abdominal cavity, gastrointestinal tract, liver, para-aortic nodes, supraclavicular nodes, inguinal nodes and spine [2]. Cutaneous metastases arising from cervical cancer are particularly rare even in the advanced stages of the disease, with its incidence ranging from $0.1 \%$ to $4.4 \%$ [1]. Mostly, they occur as a sign of disease recurrence and are associated with poor prognosis. SCC accounts for $80 \%$ of all cervical cancers but it metastasise to distant sites less commonly than adenocarcinoma [3].

There is enormous variability in clinical appearance of skin metastasis, with multiple nodules as the most common clinical appearance; less common forms include inflammatory or erysipeloid form, sclerodermoid form, alopecia neoplastica, or bullous form [4]. Cutaneous manifestations may herald the underlying disease process [5]. Zosteriform pattern is very rare type of cutaneous metastases with only a few reported cases. Many of the dermatomal metastases have been initially diagnosed as herpes zoster which is a common finding in immunocompromised cancer patients. Spontaneous pain mimicking herpes zoster has been observed in many patients with zosteriform metastases with many of them initially having been treated with antiviral drugs. ${ }^{5}$ It manifested as a sign of relapse following definite treatment of the primary tumour in most reports, but it was the presenting complaint in a few cases [6].

Only 56 cases of zosteriform pattern have been reported in the English literature since 1970 as per a meta analysis published in 2009 [7]. In males the highest prevalence of primary malignancy was SCC (22.2\%) and lung carcinoma (22.2\%). In females the highest prevalence of primary malignancy was breast carcinoma (35\%), followed by ovary carcinoma (25\%). But it was also reported in patients with melanoma, carcinoma of prostate, bladder, colon, rectum and renal pelvis [8]. However, we could not find any case of the same occurring in patients of carcinoma uterus. According to a previous report, adenocarcinomas were the commonest histopathological pattern followed by transitional carcinoma [4]. Generally, the histological features of the metastases are similar to the primary tumor, although metastases may be more anaplastic 
and exhibit less differentiation. The exact mechanism of zosteriform metastases is still speculative. It has been hypothesised that it might be due to: a) Koebnerlike reaction at the site of prior herpes zoster infection ('locus minoris resistentiae'- site of lessened resistance); b) Perineural lymphatic spread; c) spread via fenestrated vessels of the dorsal root ganglion; d) Accidental surgical implantation [4].

Metastases from the uterine cervix to the neck lymph nodes are uncommon. With more recent improved treatment of cervical cancer, supraclavicular lymphadenopathy has emerged as a more common manifestation of recurrent disease [9]. Our patient probably had secondaries in the cervical and supraclavicular lymph nodes which could not be confirmed as she was lost to follow-up.

\section{CONCLUSION}

In patients with carcinoma cervix and lesions of zosteriform skin lesions, a differential diagnosis of metastasis may be considered to avoid inadequate diagnosis and treatment. A representative biopsy sampling should be taken if the lesions are unresponsive to antiviral agents.

\section{CONSENT}

The examination of the patient was conducted according to the Declaration of Helsinki principles.

\section{REFERENCES}

1. Bellefqih S, Mezouri I, Khalil J, DiakitÃ A, Khannoussi BE, Kebdan T, et al. Skin metastasis of cervical cancer: About an unusual case. J Clin Case Rep. 2013;3:284.

2. Fagundes H, Perez CA, Grigsby PW, Lockett MA. Distant metastases after irradiation alone in carcinoma of the uterine cervix. Int J Radiat Oncol Biol Phys. 1992;24:197-204.

3. Yamauchi M, Fukuda T, Wada T, Kawanishi M, Imai K, Hashiguchi $\mathrm{Y}$, et al. Comparison of outcomes between squamous cell carcinoma and adenocarcinoma in patients with surgically treated stage III cervical cancer. Mol Clin Ocol. 2014;2:518-24.

4. Rao R, Balachandran C, Rao L. Zosteriform cutaneous metastases: A case report and brief review of literature. Indian J Dermatol Venereol Leprol, 2010;76:447-9.

5. Lenz CR, Middleton KA. Cutaneous metastasis heralding invasive ductal carcinoma of the breast in a 33 year old patient. Our Dermatol Online. 2016;7(4):415-18.

6. Kishan KYH, Rao GRR. A rare case of zosteriform cutaneous metastases from squamous cell carcinoma of hard palate. Ann Med Health Sci Res. 2013;3:127-130.

7. Savoia P, Fava P, Deboli. Zosteriform cutaneous metastases: a literature meta-analysis and a clinical report of three melanoma cases Dermatol Surg. 2009;35:1355-632.

8. Juanes JS, Escobar ML, Palicio NV, Rivas BM, Galache C, del Rio JS, et al. Zosteriform cutaneous metastasis from a breast carcinoma. Med Cutan Iber Latin Am. 2007;35:89-93.

9. López F, Rodrigo JE, Silver CE, Haigentz M, Bishop JA, Strojan P, et al. Cervical lymph node metastases from remote primary tumor sites. Head Neck. 2016;38:1-24.

Copyright by Romita Bachaspatimayum, et al. This is an open-access article distributed under the terms of the Creative Commons Attribution License, which permits unrestricted use, distribution, and reproduction in any medium, provided the original author and source are credited.

Source of Support: Nil, Conflict of Interest: None declared. 